\title{
A literature review to investigate the link between psychosocial characteristics and treatment adherence in cancer patients
}

\author{
Paraskevi Theofilou, ${ }^{1,2}$ Helen Panagiotaki ${ }^{3}$ \\ ${ }^{1}$ Panteion University, Department of Psychology; ${ }^{2}$ General Hospital Sotiria; ${ }^{3}$ General Hospital A. \\ Fleming, Athens, Greece
}

\begin{abstract}
Adherence to medication has been recognized as a key issue in health outcomes and efforts to improve patients' adherence are being made by the pharmaceutical industry, experts, and government bodies alike. This paper presents a review of these issues according to previous descriptive findings. Relevant studies written in English, published in 1976 or later, were identified through Medline, Embase and PsycInfo databases and reviewed. Review articles and clinical trials were excluded; all observational studies and surveys were considered. Articles were reviewed for any discussion of patients' characteristics and psychosocial characteristics affecting adherence to cancer treatment. The search strategy included a combination of key words adherence and cancer in titles. The major findings are summarized and presented under two main headings: i) patients' characteristics; and ii) psychosocial characteristics. In general, factors associated with increased likelihood of adherence to cancer treatment included younger age, higher education, higher income and Caucasian ethnicity. With regards to the psychosocial factors, lower levels of depression and anxiety, optimism as well as social support seemed to have a positive effect on treatment adherence. Studies of patterns of care in cancer treatment can help identify challenges in health care provided to particular subgroups of cancer patients and can aid researchers in designing studies that account for such factors in clinical and outcomes' research.
\end{abstract}

Correspondence: Paraskevi Theofilou, 12 Eratous, 14568, Athens, Greece. Tel. +30.6977.441502; +30.210.6221435 - Fax: +30.210 .6221435 .

E-mail: theofi@otenet.gr

Key words: adherence, cancer, review, patients' characteristics, psychosocial characteristics.

Conflict of interests: the authors declare no potential conflict of interests.

Received for publication: 21 February 2012.

Revision received: 10 April 2012.

Accepted for publication: 7 May 2012.

This work is licensed under a Creative Commons Attribution NonCommercial 3.0 License (CC BY-NC 3.0).

(C) Copyright T. Paraskevi and H. Panagiotaki, 2012

Licensee PAGEPress, Italy

Oncology Reviews 2012; 6:e5

doi:10.4081/oncol.2012.e5

\section{Introduction}

Cancer is the leading cause of death in economically developed countries and the second leading cause of death in developing countries. ${ }^{1,2}$ The burden of cancer is increasing in economically developing countries as a result of population aging and growth as well as, increasingly, an adoption of cancer-associated lifestyle choices, including smoking, physical inactivity, and westernized diets. With the increasing development and marketing of therapies for cancer, including the recent explosion in small molecule inhibitors that have either already been approved by the US Food and Drug Administration or are being examined in ongoing clinical trials, the issue of patient adherence has gained importance for the oncology community. ${ }^{3}$

According to the World Health Organization (WHO), adherence is a person's behavior concerning taking medication, following a diet, and making changes in lifestyle in accordance with a medical or non-medical health professional recommendations. ${ }^{4}$ Thanks to the large body of research published over recent decades, several factors have been identified with regard to their influence on adherence behavior. ${ }^{5,6}$ So far, it has been difficult to decide which factors are of the most significance and how these interact in influencing adherence behavior. ${ }^{7}$ The WHO has structured recognized influential factors into five dimensions: social/economic, therapy-related, patient-related, conditionrelated and those related to the health-care team and system. ${ }^{4}$ Key reasons for non-adherence include adverse effects or other problems with medications, such as poor instructions, poor memory, inability to pay for medications, disagreement about the need for treatment, and poor relationships between consumers and healthcare professionals. ${ }^{8-10}$ Other reasons for non-adherence include polypharmacy, ${ }_{1}^{11}$ low literacy, ${ }^{12}$ silent conditions such as hyperlipidemia, hypertension and osteoporosis, ${ }^{13}$ cultural factors, ${ }^{14}$ inadequate social support, ${ }^{15}$ depression, ${ }^{16,17}$ health beliefs ${ }^{18,19}$ or patientsi personality. ${ }^{20}$

A review of the research into cancer therapy and patient adherence showed that it has mainly focused on non-adherence to taking chemotherapy medication and attending medical appointments, whereas there is very little research on adherence for other behavioral aspects of therapy (e.g. fluid intake, weight maintenance, etc.) that are relevant across all cancers. Some studies have examined adherence to certain behavioral aspects for a specific cancer (e.g. adherence to toothpaste or gel fluoride treatment for head and neck cancers). ${ }^{21}$ However, the prevalence and assessment of non-adherence to a wide range of behavioral aspects common across all cancers has not been extensively examined. Because of their importance in promoting patient health and quality of life $(\mathrm{QoL})$, these aspects deserve further attention.

Numerous studies have examined the factors affecting how cancer patients receive treatment but for the moment there is no literature available that compiles factors associated with patients' characteris- 
tics and psychosocial characteristics in a single source. For example, it is commonly understood that older patients are generally less likely to receive cancer treatment due to their shorter life expectancies, general poorer health and the reduced risk/benefit. However, other factors may also influence receipt of treatment, even in younger patients, and need to be accounted for in observational studies and research into outcomes involving cancer. Therefore, we performed a review of the literature and information published since 1976 regarding the factors affecting treatment adherence in patients with cancer, taking into account patients' characteristics and psychosocial characteristics.

\section{Materials and Methods}

Published data assessing adherence in cancer patients from the past 35 years (from 1976 to 2010) was searched for in Medline, Embase and PsycInfo databases including the following terms: adherence, cancer, psychosocial characteristics and patient characteristics. Review articles, case reports and clinical trials were excluded; observational, clinical, and population-based studies were considered, as were survey data of physicians and oncologists. General clinical reviews that provided treatment guidelines but no original data were also excluded. The factors studied in relation to receipt of cancer treatment were roughly divided into two primary categories: patients' characteristics and psychosocial characteristics.

In order to have a more integrated view on the topic of adherence, we have also reported some results concerning the adherence in a more general context, that is the field of chronic diseases other than cancer.

\section{Results and Discussion}

Several variables have been found to be associated with adherence to cancer treatment. Some commonly cited variables are education, ${ }^{22}$ income, ${ }^{22}$ emotional states ${ }^{23-25}$ and complexity of the treatment regime. ${ }^{26}$ In addition, optimism has been found to be associated with adherence to medication taking, ${ }^{27}$ but has not been examined with adherence to cancer treatment regimens. The relevant studies that have examined the patient and psychosocial variables in relation to adherence are summarized below.

\section{Patients' characteristics Age}

Most of the studies showed that age was related to adherence in chronic diseases, although a few researchers found age not to be a factor causing non-adherence. ${ }^{28-31}$ For elderly people, the results from the various studies are not unidirectional. A large proportion of retrieved studies suggested that they might have higher adherence..$^{32-45}$ However, in contrast, some studies found that advancing age affected adherence among elderly people in a negative way. ${ }^{46-48}$ Regarding cancer treatment, all of the studies examined found that older patients received chemotherapy showed less adherence than younger patients. ${ }^{49-57}$ Of these studies, 7 provided numerical data to support this conclusion. ${ }^{50-54,56,57}$ Five of the studies demonstrated a statistically significant difference in chemotherapy use between older and younger patients, ${ }^{51-54,56}$ although only 2 of these provided data specific to metastatic cancer. ${ }^{52,53}$ In a prospective survey of qualified specialists in France, the authors noted that, of the women receiving chemotherapy, $82 \%$ in the younger age group received the standard dose and cycle length compared with only $62 \%$ of those in the older age group. ${ }^{53}$ In a survey administered to medical and clinical oncologists in the UK, ask- ing which factors were important in deciding whether to recommend chemotherapy to patients with metastatic breast cancer, patient age was considered to be quite important or very important for $58.6 \%$ of oncologists surveyed. ${ }^{58}$

Several studies offered reasons to explain why older women were less adherent to chemotherapy. The lower proportion of older women with breast cancer receiving chemotherapy may reflect an increased number of co-morbidities and worse general health among these women..$^{53}$ For example, among British oncologists, frailty and concurrent medical conditions were considered quite important or very important to $93.1 \%$ and $82.8 \%$ of surveyed clinicians, respectively, compared to the $58.6 \%$ of oncologists who considered age to be of importance..$^{58}$ Of the 10 studies in this review citing the impact of age on chemotherapy use, only two adjusted for co-morbidities, ${ }^{51,52}$ one of which ${ }^{18}$ provided data specific to metastatic breast cancer. In both studies, multivariate analyses revealed a stronger inverse association of increasing age and chemotherapy use than that of co-morbidity and chemotherapy use. The higher prevalence of hormone receptor (estrogen or progesterone receptor) positive tumors among postmenopausal women than premenopausal women ${ }^{59}$ and, therefore, more frequent use of hormone therapy, also contributes to this observation. It has been suggested that elderly patients have cancers with lower proliferative indices, and that they will derive less benefit from standard chemotherapy; ${ }^{60}$ however, the elderly are frequently underrepresented in cancer clinical trials. Although elderly (65 years of age or older) patients make up $63 \%$ of cancer patients in the US, they represent only $25 \%$ of the cancer clinical trial participants. ${ }^{61}$ Whether this deficit is due to fear and misunderstanding of older patients, physician bias against enrolling older patients, or overly stringent eligibility criteria that limit the number of elderly patients, their underrepresentation makes it difficult to assess the risks and benefits of cancer chemotherapeutic regimens and may partially explain the inverse relationship between age and chemotherapy use. Also, elderly patients may have problems in vision, hearing and memory. In addition, they may have greater difficulty in following therapy instructions due to cognitive impairment or other physical difficulties, such as having problems in swallowing tablets, opening drug containers, handling small tablets, distinguishing colors or identifying markings on drugs. ${ }^{62-69}$

\section{Education}

Several studies found that better educated patients might have higher adherence, ${ }^{70-72}$ while some studies found no association. ${ }^{73-78}$ Intuitively, it may be expected that patients with higher levels of educational should be better informed about the disease and therapy and, therefore, demonstrate greater adherence. However, Di Matteo found that even highly educated patients may not understand their medical condition or may not perceive the benefits of adherence to their medication regimen. ${ }^{79}$ Other researchers showed that patients with lower levels of education show better adherence. ${ }^{80}$ Four studies discussed education level in relation to chemotherapy treatment, ${ }^{81,58,55,56}$ as well as other adjuvant therapies, such as radiation and hormone therapy; only 2 provided quantitative data related to chemotherapy, $, 2,55,56$ and only one was specific to metastatic breast cancer. ${ }^{58}$ Peele and colleagues stated that educated women were significantly more likely to adhere to treatment with adjuvant therapy, including chemotherapy, hormone therapy, and combination therapy, although the study did not distinguish between cases based on disease severity and treatment. ${ }^{56}$ Mitchell and colleagues reported that being less educated was statistically significantly and inversely correlated to a belief in religious intervention in place of treatment; $; 5$ it is presumed that the treatment likely included chemotherapy due to inclusion of women with advancedstage breast cancer in the study population. From a qualitative perspective, Ashing-Giwa and colleagues, when discussing various adjuvant 
therapies including chemotherapy, reported that less-educated women in the United States were less informed about breast cancer itself, as well as about resources and treatments. They were less adherent to treatment and less proactive in seeking medical care. ${ }^{81}$ In the UK, $13.8 \%$ of clinicians ranked education as an important factor influencing their recommendation for palliative chemotherapy to women with metastatic breast cancer. ${ }^{58}$

\section{Cost of therapy and income}

Cost is a crucial issue in patient adherence especially for patients with chronic disease as treatment could be life-long. ${ }^{83-86}$ Healthcare expenditure could be a large portion of living expenses for patients suffering from chronic disease. Cost and income are two interrelated fac tors. Healthcare cost should not be a heavy burden if the patient has a relatively high income or health insurance. A number of studies found that patients who had no insurance cover, ${ }^{87-89}$ or who had low income, ${ }^{90-95}$ were more likely to be non-adherent to treatment. However, even for patients with health insurance, health expenses could still be a problem. More than one in 10 senior citizens in the USA reported using less of their required medications because of cost. ${ }^{96}$ Nevertheless, in other cases, income was not related to adherence level. ${ }^{97-100}$ Three studies discussed income in relation to chemotherapy treatment: 2 in the US ${ }^{101}$ and one in the UK. ${ }^{102}$ Of the 2 studies that provided numerical data, neither observed a significant difference in the proportions of patients receiving chemotherapy by income, although one suggested that their observation that uninsured, lower income women were less likely to adhere to chemotherapy may have reached statistical significance with a larger sample size. A qualitative study of community health professionals working with different patient populations reported that individuals with lower income may not have sufficient awareness of the disease, resources, and treatments, and are not as proactive about seeking medical care.

\section{Ethnicity}

Race as a factor causing non-adherence has been studied fairly widely in the USA and European countries. Caucasians are believed to have good adherence according to some studies, ${ }^{103-106}$ while AfricanAmericans, Hispanics and other minorities were found to have comparatively poor adherence. ${ }^{107-113}$ However, a plausible explanation for this may be due to the patients' lower socio-economic status and language barriers affecting the minority ethnic races in the study countries. Hence, due to these confounding variables, ethnicity may not be a true predictive factor of poorer adherence. Five studies, all conducted in the US, considered race to be a factor in predicting adherence to chemotherapy in breast cancer patients..$^{52,55,81,114,115}$ Only one study presented data specific to metastatic breast cancer, ${ }^{52}$ with the remainder considering all cases (stages I through IV) in aggregate. In a study by Du and Goodwin, ${ }^{52}$ the proportions of black and white women with stage IV breast cancer who received chemotherapy were similar (26.8\% vs. $26.5 \%$, respectively), although fewer women whose race was classified as other received chemotherapy (18.2\%). Two other studies (not specific to stage IV disease) reported very small differences in the percentages of Caucasian, African-American, and Hispanic women with breast cancer treated with chemotherapy; both noted that higher proportions of Caucasian women $(81.3 \%$ and $67.0 \%)$ than African-American women (80.0\% and $46.5 \%)$ or Hispanic women (52.4\%) received chemotherapy, ${ }^{114,115}$ although these differences either were not statistically significant or statistical significance was not evaluated. ${ }^{115}$

\section{Psychosocial characteristics}

Emotional states: depression, anxiety and adherence

Research has indicated that emotional states such as depression and anxiety may be associated with adherence. A recent meta-analysis conducted across medical regimens by Di Matteo, Lepper, and Crogham ${ }^{116}$ reported that depressed patients were 3 times as likely as non-depressed patients to be non-adherent, but found that anxiety was not significantly associated with adherence. A few studies on cancer therapy regimens have examined the relationship between emotional states and adherence. For example, Ayres et al. ${ }^{117}$ prospectively examined psychosocial aspects in order to predict adherence to administered chemotherapy appointments for grade IV cancer. Using discriminant analysis, patients who exhibited more anxiety and depression were more likely to adhere by attending chemotherapy appointments. Furthermore, Richardson et al. ${ }^{24}$ found that depression at six months was significantly correlated with non-adherence in patients who took oral chemotherapy medication intermittently. Finally, Itano et al. ${ }^{23}$ found that those with higher state anxiety were more likely to adhere to attending chemotherapy and blood laboratory work appointments.

In summary, most research indicates that depression plays an important part in predicting non-adherence. From a conceptual standpoint, it can be postulated that depression may affect cognitions (e.g. outcome expectancies, perceived benefits and barriers) and motivation to follow through with treatment recommendations. However, the role that anxiety plays with regard to adherence is less clear. Across medical regimens, research has indicated that anxiety has had no significant effect on adherence. However, some of the research into cancer and adherence has indicated that anxiety is positively correlated with adherence. Some have argued that anxiety can be associated with enhanced adherence because anxious individuals have been shown to be more hypervigilant and have an increased tendency to seek medical assistance. $^{118}$

\section{Optimism and adherence}

Optimism has been found to predict a better $\mathrm{QoL}^{119}$ and promote lower distress levels among breast cancer patients. ${ }^{120}$ With regard to adherence, some research has indicated that optimism is associated with a more positive attitude toward medication taking. ${ }^{121}$ Carver, Lehman and Antoni ${ }^{122}$ argued that optimism keeps patients involved and engaged in treatment goals, leading to an improved psychological well-being. It also seems likely that optimistic patients focus on positive aspects of treatment, or benefits, and are more likely to adhere.

\section{Social support/partners}

The general findings from these articles showed that patients who had emotional support and help from family members, friends or healthcare providers were more likely to be adherent to the treatment. ${ }^{123-133}$ The social support helps patients in reducing negative attitudes to treatment, being motivated and also remembering to implement the treatment. Two studies provided numerical data regarding the impact of a spouse or significant other on the adherence to chemotherapy treatment ${ }^{52,82}$ one of which provided data specific to metastatic breast cancer. ${ }^{52,18}$ 0sborne $e t$ al. reported that married women were more likely to adhere to chemotherapy than unmarried women (married 12.3\% vs. unmarried 9.1\%). Du and Goodwin also reported similar findings (married $37.4 \%$ vs. unmarried 20.7\%). One study suggested that unmarried women might receive chemotherapy less often due to patients' personal concerns over postoperative assistance and transportation or the amount of out-of-pocket expense for treatment, or due to a doctor's decision not to discuss such treatment options because of these assumptions. ${ }^{82}$ of British clinicians surveyed, $51.7 \%$ reported that the patient's social support was an important factor in their decision to give palliative chemotherapy to women with metastatic breast cancer. ${ }^{58}$

Details of studies included in the review are listed in Table 1. 


\section{Conclusions}

In this review, we attempted to identify general factors related to adherence. Original studies investigating adherence in cancer patients were retrieved. However, in order to have a more integrated view on the specific topic, we have also reported some results from different diseases, population settings and different countries. In the process, we identified a wide array of influencing factors. Although the effect of some factor on adherence is complex and not unequivocal, the review process has identified several factors with consistent impact on adherence. Factors affecting receiving treatment in patients with cancer have been well studied, but for the moment there is no literature available that compiles factors associated with patients' characteristics and psychosocial characteristics in a single source.

The effect of demographic factors (e.g. age, ethnicity and educational level) on adherence is complicated by the fact that they may not be truly independent. In fact, demographic factors are related to patient cultural, socioeconomic and psychological backgrounds. Thus, future studies on adherence should not focus on demographic factors alone. Psychosocial factors such as psychological well-being, social support, patients' beliefs and their motivation regarding therapy could be classified as crucial factors. Since the 1990s, research has focused more on the patient-provider relationship, patient's mental health and patient's beliefs about their therapy. For individuals with chronic diseases, and specifically in cancer patients, a favorable quality of life would enhance their treatment adherence. In fact, the effects of patient's beliefs, emotional states, health knowledge and relationship with the healthcare

Table 1. Details of the studies included in the review.

\begin{tabular}{|c|c|c|c|c|c|}
\hline Study & Type of study & Patients & Age (years) & Statistical analysis & Factors of adherence \\
\hline Caban et al. ${ }^{49}$ & Population-based & 234 & 56 (range 24-86) & $\begin{array}{c}\text { Hierarchical } \\
\text { Logistic Regression }\end{array}$ & Age \\
\hline Diab et al. ${ }^{50}$ & Study population & 307.115 & $\geq 55$ & Linear Associations & Age \\
\hline Du et al..$^{51}$ & Population-based & 35.060 & $\geq 65$ & Multivariate analysis & Age \\
\hline Du et al..$^{52}$ & Study population & 1.129 & $\geq 65$ & Logistic regression & $\begin{array}{l}\text { Age, ethnicity, } \\
\text { social support }\end{array}$ \\
\hline Freyer et al. ${ }^{53}$ & Prospective survey & 1.009 & $\begin{array}{c}500 \text { from } 65 \text { to } 74 \text { (average } 68.6 \text { ) } \\
\text { and } 509>75 \text { (average } 79.6 \text { ) }\end{array}$ & Correlation & Age \\
\hline Golledge et al. . $^{4}$ & Study population & 784 & $\geq 60$ & Correlation & Age \\
\hline Mitchell et al. ${ }^{55}$ & Clinical & 682 & $\geq 40$ & Factor analysis & Age, education, ethnicity \\
\hline Peele et al. ${ }^{56}$ & Clinical & 386 & Not stated & Not stated & Age, education \\
\hline Wyld et al. ${ }^{57}$ & Clinical & 378 & $\begin{array}{c}55-69 \text { and }>70 \\
\text { (comparative study) }\end{array}$ & $\begin{array}{l}\text { Statistical significance } \\
\text { tested with } x^{2}\end{array}$ & Age \\
\hline Dunnwald et al. ${ }^{59}$ & Population-based & 155.175 & $\geq 30$ & Multivariate Cox regression modelling & Age \\
\hline Hutchins et al. ${ }^{61}$ & Population-based & 16.396 & $>65$ & Two-tailed P values & Age \\
\hline Benner et al. ${ }^{62}$ & Retrospective cohort & 35.401 & $>65$ & $\begin{array}{l}\text { Generalized linear models } \\
\text { for repeated measures }\end{array}$ & Age \\
\hline Chizzola et al. ${ }^{63}$ & Clinical & 485 & 54 (range 17-86) & $\begin{array}{l}\text { Chi-square test, students t-test, } \\
\text { ultivariate log-line or regression analysis }\end{array}$ & Age \\
\hline Theofilou $^{64}$ & Clinical & 168 & 62 & $\begin{array}{l}\text { Independent-samples t-test, } \\
\text { one-way ANOVA, correlation }\end{array}$ & Age \\
\hline Jeste et al. ${ }^{65}$ & Clinical & 110 & Not stated & Stepwise regression analysis & Age \\
\hline Murray et al. ${ }^{66}$ & Clinical & 140 & Not stated & Not stated & Age \\
\hline Nikolaus et al. ${ }^{67}$ & Clinical & 119 & Not stated & Not stated & Age \\
\hline Okuno et al. ${ }^{68}$ & Clinical & 220 & $\begin{array}{c}\geq 60 \\
\text { (mean age of } 75.7 \text { ) }\end{array}$ & Multiple logistic regression analysis & Age \\
\hline Ashing-Giwa et al. ${ }^{81}$ & Clinical & 102 & Not stated & Not stated & Education, ethnicity \\
\hline Osborne et al. ${ }^{82}$ & Population-based & 32.268 & $\geq 65$ & Not stated & Education, social support \\
\hline Liu et al. ${ }^{101}$ & Population-based & 13.703 & Not stated & Logistic regression & Income \\
\hline Downing et al. ${ }^{102}$ & Population-based & 12.768 & Not stated & $\begin{array}{c}\text { Logistic regression and } \\
\text { Cox proportional hazards analyses }\end{array}$ & Income \\
\hline Maloney et al. ${ }^{114}$ & Clinical & 52 & 56.6 & Chi-squared and tailed t-tests & Ethnicity \\
\hline Shavers et al. ${ }^{115}$ & Epidemiology & 3.978 & $21-34$ & Multivariate analyses & Ethnicity \\
\hline Richardson et al..$^{24}$ & Clinical & 92 & $18-86$ & Not stated & Emotional states \\
\hline Carver et al. ${ }^{119}$ & Clinical & 163 & Not stated & Correlation and multivariate analyses & Optimism \\
\hline Epping-Jordan et al. ${ }^{120}$ & Clinical & 80 & Not stated & Regression analyses & Optimism \\
\hline Godin et al..$^{121}$ & Clinical & 376 & Not stated & Regression analyses & Optimism \\
\hline Carver et al. ${ }^{122}$ & Clinical & 235 & 27 to 87 (mean age of 53.59 ) & Regression coefficients & Optimism \\
\hline
\end{tabular}

ANOVA, analysis of variance. 
provider are very complex because these factors are interrelated with each other. The interaction is a little like antibiotic combinations. Sometimes the effect is additive or synergistic while other times the effect is antagonistic. However, due to the design of the studies performed so far, it is difficult, if not impossible, to differentiate precisely between whether the interaction between these factors has been additive, synergistic or antagonistic. More robust and better designed studies would be needed in future to clarify these interactions. Certainly, there are some limitations in the current review. Three electronic databases, Medline, Embase and PsycInfo, were searched and only English articles were included. It might be possible that some informative studies in other literature databases or in other languages were omitted. Also, from the review of the literature starting from the 1970 s to identify relevant factors relating to therapeutic adherence, the evidence indicates that non-adherence is still commonplace and no substantial change has occurred despite the large number of studies attempting to address and highlight the problem. In addition, too few studies are being carried out systematically to quantify the impact of non-adherence on health and financial outcomes. The magnitude of the impact of non-adherence needs to be studied in future research due to the potentially enormous implications of poor adherence on clinical and economic outcomes. Finally, few studies on adherence have been performed in Asia and developing countries where most of the world's population now lives. More studies on factors influencing adherence in these countries or regions would be helpful to fill the gap in our knowledge and help formulate international strategies to reduce non-adherence.

\section{References}

1. World Health Organization. The Global Burden of Disease: 2004 Update. Geneva: World Health Organization; 2008.

2. Theofilou P. Quality of life outcomes in patients with breast cancer. Oncology Reviews 2012;6:e2.

3. De Geest S, Sabate E. Adherence to long-term therapies: Evidence for action. Eur J Cardiovasc Nurs 2003;2:323.

4. Sabate E. Adherence to long - term therapies: evidence for action. Geneva: World Health Organization; 2003.

5. Theofilou P, Reyes Saborit A. Predictors of asthma treatment adherence. J Psychol Psychother 2012;3:1-2.

6. Theofilou P. Factors affecting level of compliance in chronic patients. J Int Med 2011;2:1-2.

7. Levensky ER, O'Donohue WT, William T. Patient adherence and nonadherence to treatments. In: O'Donohue WT, Levensky, ER, editors. Promoting treatment adherence: A practical handbook for health care providers. Thousand Oaks, CA: Sage Publications, inc.; 2006. pp. 3-14.

8. Theofilou P. Improved quality of life, functional and emotional status: the doctor patient relationship. J Primary Health Care 2011;1:1-2.

9. Theofilou P. Interventions to support medication adherence in individuals with chronic disease: the role of health professionals. J Commun Med Health Educat [In press].

10. Theofilou P. Identifying risk factors associated with compliance to medication in elderly kidney transplant patients. J Transplant Technol Res 2012;2:1-2.

11. Austin RP. Polypharmacy as a risk factor in the treatment of type 2 diabetes. Diabet Spectrum 2006;19:13-6.

12. Murray MD, Wu J, Tu W, et al. Health literacy predicts medication adherence. Clin Pharmacol Ther 2004;75:P76.

13. Gold DT, Alexander IM, Ettinger MP. How can osteoporosis patients benefit more from their therapy? Adherence issues with bisphosphonate therapy. Ann Pharmacother 2006;40:1143-50.
14. Chia LR, Schlenk EA, Dunbar-Jacob J. Effect of personal and cultural beliefs on medication adherence in the elderly. Drugs Aging 2006;23:191-202.

15. Theofilou P. The relation of social support to mental health and locus of control in chronic kidney disease. J Renal Nurs 2012;4:18-22.

16. Theofilou P. Non - compliance with medical regimen in haemodialysis treatment: a case study. Case Rep Nephrol 2011;1-4.

17. Theofilou P. Major depression in women diagnosed with breast cancer. J Int Med [In press].

18. Theofilou P. Quality of life and mental health in haemodialysis and peritoneal dialysis patients: the role of health beliefs. Int Urol Nephrol 2012;44:245-53.

19. Theofilou P, Reyes Saborit A. Health locus of control and diabetes adherence. J Psychol Psychother 2012;3:1-2.

20. Theofilou P. The impact of personality traits on quality of life in patients diagnosed with breast cancer. J Women Health Care 2011;1:1-2.

21. Bransfield D, Horiot J, Bone M. High compliance with fluoride treatment by patients irradiated for head and neck tumors: A theoretical interpretation. J Psychosoc Oncol 1986;4:43-51.

22. DiMatteo MR, DiNicola DD. Acheving patient compliance. Elmsford, NY: Pergamon; 1982.

23. Itano J, Tanabe P, Lum J, et al. Compliance and noncompliance in cancer patients. Progr Clin Biol Res 1983;120:483-95.

24. Richardson J, Marks G, Johnson C, et al. Path model of multidimensional compliance with cancer therapy. Health Psychol 1987;6:183207.

25. Ayres A, Hoon P, Franzoni J, et al. Influence of mood and adjustment to cancer on compliance with chemotherapy among breast cancer patients. J Psychosom Res 1994;38:393-402.

26. Sackett DL, Haynes BR. Compliance with therapeutic regimens. Baltimore: Johns Hopkins University Press; 1976.

27. Milam JE, Richardson JL, Marks G, et al. The roles of dispositional optimism and pessimism in HIV disease progression. Psychol Health 2004;19:167-81.

28. Lorenc L, Branthwaite A. Are older adults less compliant with prescribed medication than younger adults? Br J Clin Psychol 1993;32:485-92.

29. Menzies R, Rocher I, Vissandjee B. Factors associated with compliance in treatment of tuberculosis. Tuber Lung Dis 1993;74:32-7.

30. Wai CT, Wong ML, Ng S. Utility of the health belief model in predicting compliance of screening in patients with chronic hepatitis B. Aliment Pharmacol Ther 2005;21:1255-62.

31. Wild MR, Engleman HM, Douglas NJ. Can psychological factors help us to determine adherence to CPAP? A prospective study. Eur Respir J 2004;24:461-5.

32. Viller F, Guillemin F, Briancon S. Compliance to drug treatment of patients with rheumatoid arthritis: a 3 year longitudinal study. J Rheumatol 1999;26:2114-22.

33. Didlake RH, Dreyfus K, Kerman RH. Patient noncompliance: a major cause of late graft failure in cyclosporine-treated renal transplants. Transplant Proc 1988;20:63-9.

34. Frazier PA, Davis-Ali SH, Dahl KE. Correlates of noncompliance among renal transplant recipients. Clin Transplant 1994;8:550-7.

35. Hertz RP, Unger AN, Lustik MB. Adherence with pharmacotherapy for type 2 diabetes: a retrospective cohort study of adults with employer-sponsored health insurance. Clin Ther 2005;27:1064-73.

36. Kim YS, Sunwoo S, Lee HR. Determinants of non-compliance with lipid-lowering therapy in hyperlipidemic patients. Pharmacoepidemiol Drug Saf 2002;11:593-600.

37. McLane CG, Zyzanski SJ, Flocke SA. Factors associated with medication noncompliance in rural elderly hypertensive patients. Am J Hypertens 1995;8:206-9.

38. Monane M, Bohn RL, Gurwitz JH. Compliance with antihyperten- 
sive therapy among elderly Medicaid enrollees: the roles of age, gender, and race. Am J Public Health 1996;86:1805-8.

39. Norman SA, Marconi KM, Schezel GW. Beliefs, social normative influences, and compliance with antihypertensive medication. Am J Prev Med 1985;1:10-7.

40. Schweizer RT, Rovelli M, Palmeri D. Noncompliance in organ transplant recipients. Transplantation 1990;49:374-7.

41. Senior V, Marteau TM, Weinman J. Self - reported adherence to cholesterol-lowering medication in patients with familial hypercholesterolaemia: the role of illness perceptions. Cardiovasc Drugs Ther 2004;18:475-81.

42. Shaw E, Anderson JG, Maloney M. Factors associated with noncompliance of patients taking antihypertensive medications. Hosp Pharm 1995;30:201-3, 206-7.

43. Shea S, Misra D, Ehrlich MH. Correlates of nonadherence to hypertension treatment in an inner-city minority population. Am J Public Health 1992;82:1607-12.

44. Sirey JA, Bruce ML, Alexopoulos GS. Stigma as a barrier to recovery: Perceived stigma and patient-rated severity of illness as predictors of antidepressant drug adherence. Psychiatr Serv 2001; 52:1615-20.

45. Buck D, Jacoby A, Baker GA. Factors influencing compliance with antiepileptic drug regimes. Seizure 1997;6:87-93.

46. Balbay 0, Annakkaya AN, Arbak P. Which patients are able to adhere to tuberculosis treatment? A study in a rural area in the northwest part of Turkey. Jpn J Infect Dis 2005;58:152-8.

47. Benner JS, Glynn RJ, Mogun H. Long - term persistence in use of statin therapy in elderly patients. JAMA 2002;288:455-61.

48. Okuno J, Yanagi H, Tomura S. Compliance and medication knowledge among elderly Japanese home-care recipients. Eur J Clin Pharmacol 1999;55:145-9.

49. Caban ME, Nosek MA, Graves D, et al. Breast carcinoma treatment received by women with disabilities compared with women without disabilities. Cancer 2002;94:1391-6.

50. Diab SG, Elledge RM, Clark GM. Tumor characteristics and clinical outcome of elderly women with breast cancer. J Natl Cancer Inst 2000;92:550-6.

51. Du X, Goodwin JS. Increase of chemotherapy use in older women with breast carcinoma from 1991 to 1996. Cancer 2001;92:730-7.

52. Du X, Goodwin JS. Patterns of use of chemotherapy for breast cancer in older women: findings from Medicare claims data. J Clin Oncol 2001;19:1455-61.

53. Freyer G, Braud AC, Chaibi P. Dealing with metastatic breast cancer in elderly women: results from a French study on a large cohort carried out by the 'Observatory on Elderly Patients'. Ann Oncol 2006;17:211-6.

54. Golledge J, Wiggins JE, Callam MJ. Age-related variation in the treatment and outcomes of patients with breast carcinoma. Cancer 2000;88:369-74.

55. Mitchell J, Lannin DR, Mathews HF, Swanson MS. Religious beliefs and breast cancer screening. J Womens Health (Larchmt) 2002;11:907-15.

56. Peele PB, Siminoff LA, Xu Y, Ravdin PM. Decreased use of adjuvant breast cancer therapy in a randomized controlled trial of a decision aid with individualized risk information. Med Decis Making 2005;25:301-7.

57. Wyld L, Garg DK, Kumar ID, et al. Stage and treatment variation with age in postmenopausal women with breast cancer: compliance with guidelines. Br J Cancer 2004;90:1486-91.

58. Grunfeld EA, Ramirez AJ, Maher EJ. Chemotherapy for advanced breast cancer: what influences oncologists' decision-making? Br J Cancer 2001;84:1172-8.

59. Dunnwald LK, Rossing MA, Li CI. Hormone receptor status, tumor characteristics, and prognosis: a prospective cohort of breast can- cer patients. Breast Cancer Res 2007;9:R6.

60. Downey L, Livingston R, Stopeck A. Diagnosing and treating breast cancer in elderly women: a call for improved understanding. J Am Geriatr Soc 2007;55:1636-44.

61. Hutchins LF, Unger JM, Crowley JJ, et al. Underrepresentation of patients 65 years of age or older in cancer-treatment trials. N Engl J Med 1999;341:2061-7.

62. Benner JS, Glynn RJ, Mogun H. Long - term persistence in use of statin therapy in elderly patients. JAMA 2002;288:455-61.

63. Chizzola PR, Mansur AJ, da Luz PL. Compliance with pharmacological treatment in outpatients from a Brazilian cardiology referral center. Sao Paulo Med J 1996;114:1259-64.

64. Theofilou P. Medication adherence in Greek hemodialysis patients: The contribution of depression and health cognitions. Int J Behav Med 2012:1-8.

65. Jeste SD, Patterson TL, Palmer BW. Cognitive predictors of medication adherence among middle-aged and older outpatients with schizophrenia. Schizophr Res 2003;63:49-58.

66. Murray MD, Darnell J, Weinberger M. Factors contributing to medication noncompliance in elderly public housing tenants. Drug Intell Clin Pharm 1986;20:146-52.

67. Nikolaus T, Kruse W, Bach M. Elderly patients' problems with medication. An in-hospital and follow-up study. Eur J Clin Pharmacol 1996;49:255-9.

68. Okuno J, Yanagi H, Tomura S. Is cognitive impairment a risk factor for poor compliance among Japanese elderly in the community? Eur J Clin Pharmacol 2001;57:589-94.

69. Stewart RB, Caranasos GJ. Medication compliance in the elderly. Med Clin North Am 1989;73:1551-63.

70. Apter AJ, Boston RC, George M. Modifiable barriers to adherence to inhaled steroids among adults with asthma: it's not just black and white. J All Clin Immunol 2003;111:1219-26.

71. Ghods AJ, Nasrollahzadeh D. Noncompliance with immunnosuppressive medications after renal transplantation. Exp Clin Transplant 2003;1:39-47.

72. Yavuz A, Tuncer M, Erdogan 0. Is there any effect of compliance on clinical parameters of renal transplant recipients? Transplant Proc 2004;36:120-1.

73. Horne R, Weinman J. Patients' beliefs about prescribed medicines and their role in adherence to treatment in chronic physical illness. J Psychosom Res 1999;47:555-67.

74. Kaona FA, Tuba M, Siziya S. An assessment of factors contributing to treatment adherence and knowledge of TB transmission among patients on TB treatment. BMC Public Health 2004;29:68.

75. Norman SA, Marconi KM, Schezel GW. Beliefs, social normative influences, and compliance with antihypertensive medication. Am J Prev Med 1985;1:10-7.

76. Spikmans FJ, Brug J, Doven MM. Why do diabetic patients not attend appointments with their dietitian? J Hum Nutr Diet 2003;16:151-8.

77. Stilley CS, Sereika S, Muldoon MF. Psychological and cognitive function: predictors of adherence with cholesterol lowering treatment. Ann Behav Med 2004;27:117-24.

78. Wai CT, Wong ML, Ng S. Utility of the health belief model in predicting compliance of screening in patients with chronic hepatitis B. Aliment Pharmacol Ther 2005;21:1255-62.

79. DiMatteo MR. Patient adherence to pharmacotherapy: the importance of effective communication. Formulary 1995;30:596-8, 601-2, 605 .

80. Kyngas $\mathrm{H}$, Lahdenpera T. Compliance of patients with hypertension and associated factors. J Ad Nurs 1999;29:832-9.

81. Ashing-Giwa KT, Padilla G, Tejero J. Understanding the breast cancer experience of women: a qualitative study of African American, Asian American, Latina and Caucasian cancer survivors. 
Psychooncology 2004;13:408-28.

82. Osborne C, Ostir GV, Du X, et al. The influence of marital status on the stage at diagnosis, treatment, and survival of older women with breast cancer. Breast Cancer Res Treat 2005;93:41-7.

83. Connelly CE. Compliance with outpatient lithium therapy. Perspect Psychiatr Care 1984;22:44-50.

84. Ellis JJ, Erickson SR, Stevenson JG. Suboptimal statin adherence and discontinuation in primary and secondary prevention populations. J Gen Intern Med 2004;19:638-45.

85. Ponnusankar S, Surulivelrajan M, Anandamoorthy N. Assessment of impact of medication counseling on patients' medication knowledge and compliance in an outpatient clinic in South India. Patient Educ Couns 2004;54:55-60.

86. Shaw E, Anderson JG, Maloney M. Factors associated with noncompliance of patients taking antihypertensive medications. Hosp Pharm 1995;30:201-3, 206-7.

87. Choi-Kwon S, Kwon SU, Kim JS. Compliance with risk factor modification: early-onset versus late-onset stroke patients. Eur Neurol 2005;54:204-11.

88. Kaplan RC, Bhalodkar NC, Brown EJ. Race, ethnicity, and sociocultural characteristics predict noncompliance with lipid - lowering medications. Prev Med 2004;39:1249-55.

89. Swett C Jr, Noones J. Factors associated with premature termination from outpatient treatment. Hosp Commun Psychiatry 1989;40:947-51.

90. Apter AJ, Reisine ST, Affleck G. Adherence with twice-daily dosing of inhaled steroids. Socioeconomic and health-belief differences. Am J Respir Crit Care Med 1998;157:1810-7.

91. Benner JS, Glynn RJ, Mogun H. Long-term persistence in use of statin therapy in elderly patients. JAMA 2002;288:455-61.

92. Berghofer G, Schmidl F, Rudas S. Predictors of treatment discontinuity in outpatient mental health care. Soc Psychiatry Psychiatr Epidemiol 2002;37:276-82.

93. Ghods AJ, Nasrollahzadeh D. Noncompliance with immunnosuppressive medications after renal transplantation. Exp Clin Transplant 2003;1:39-47.

94. Hernandez-Ronquillo L, Tellez-Zenteno JF, Garduno-Espinosa J. Factors associated with therapy noncompliance in type-2 diabetes patients. Salud Publica Mex 2003;45:191-7.

95. Mishra P, Hansen EH, Sabroe S. Socio-economic status and adherence to tuberculosis treatment: a case-control study in a district of Nepal. Int J Tuberc Lung Dis 2005;9:1134-9.

96. Congressional Budget Office. Prescription drug coverage and medicare's fiscal challenges; 2003. http://www.cbo.gov/showdoc. cfm?index $=4159 \&$ sequence $=0$ Accessed: 1 March 2007 .

97. Lim T0, Ngah BA. The Mentakab hypertension study project. Part II - why do hypertensives drop out of treatment? Singapore Med J 1991;32:249-51.

98. Norman SA, Marconi KM, Schezel GW. Beliefs, social normative influences, and compliance with antihypertensive medication. Am J Prev Med 1985;1:10-7.

99. Patal RP, Taylor SD. Factors affecting medication adherence in hypertensive patients. Ann Pharmacother 2002;36:40-5.

100.Stilley CS, Sereika S, Muldoon MF. Psychological and cognitive function: predictors of adherence with cholesterol lowering treatment. Ann Behav Med 2004;27:117-24.

101.Liu MJ, Hawk H, Gershman ST. The effects of a National Breast and Cervical Cancer Early Detection Program on social disparities in breast cancer diagnosis and treatment in Massachusetts. Cancer Causes Control 2005;16:27-33.

102.Downing A, Prakash K, Gilthorpe MS, et al. Socioeconomic background in relation to stage at diagnosis, treatment and survival in women with breast cancer. Br J Cancer 2007;96:836-40.

103.Didlake RH, Dreyfus K, Kerman RH. Patient noncompliance: a major cause of late graft failure in cyclosporine-treated renal transplants. Transplant Proc 1988;20:63-9.

104.Raiz LR, Kilty KM, Henry ML. Medication compliance following renal transplantation. Transplantation 1999;68:51-5.

105.Thomas LK, Sargent RG, Michels PC. Identification of the factors associated with compliance to therapeutic diets in older adults with end stage renal disease. J Ren Nutr 2001;11:80-9.

106.Yu YF, Nichol MB, Yu AP. Persistence and adherence of medications for chronic overactive bladder/urinary incontinence in the California medicaid program. Value Health 2005;8:495-505

107.Butterworth JR, Banfield LM, Iqbal TH. Factors relating to compliance with a gluten-free diet in patients with coeliac disease: comparison of white Caucasian and South Asian patients. Clin Nutr 2004;23:1127-34

108.Dominick KL, Golightly YM, Bosworth HB. Racial differences in analgesic/anti-inflammatory medication adherence among patients with osteoarthritis. Ethn Dis 2005;15:116-22.

109.Leggat JE Jr, Orzol SM, Hulbert - Shearon TE. Noncompliance in hemodialysis: predictors and survival analysis. Am J Kidney Dis 1998;32:139-45.

110.Monane M, Bohn RL, Gurwitz JH. Compliance with antihypertensive therapy among elderly Medicaid enrollees: the roles of age, gender, and race. Am J Public Health 1996;86:1805-8.

111.Opolka JL, Rascati KL, Brown CM. Role of ethnicity in predicting antipsychotic medication adherence. Ann Pharmacother 2003; 37:625-30.

112.Schweizer RT, Rovelli M, Palmeri D. Noncompliance in organ transplant recipients. Transplantation 1990;49:374-7.

113.Spikmans FJ, Brug J, Doven MM. Why do diabetic patients not attend appointments with their dietitian? J Hum Nutr Diet $2003 ; 16: 151-8$.

114.Maloney N, Koch M, Erb D. Impact of race on breast cancer in lower socioeconomic status women. Breast J 2006;12:58-62.

115.Shavers VL, Harlan LC, Stevens JL. Racial/ethnic variation in clinical presentation, treatment, and survival among breast cancer patients under age 35. Cancer 2003;97:134-47.

116.DiMatteo M, Lepper H, Croghan TW. Depression is a risk factor for noncompliance with medical treatment: Meta-analysis of the effects of anxiety and depression on patient adherence. Arch Int Med 2000;160:2101-7.

117.Ayres A, Hoon P, Franzoni J, et al. Influence of mood and adjustment to cancer on compliance with chemotherapy among breast cancer patients. J Psychosom Res 1994;38:393-402.

118.Miller SM. Monitoring and blunting: Validation of a questionnaire to assess styles of information seeking under threat. J Pers Soc Psychol 1987;52:345-53.

119.Carver CS, Smith RG, Antoni MH, et al. Optimistic personality and psychosocial well-being during treatment predict psychosocial well-being among long-term survivors of breast cancer. Health Psychol 2005;24:508-16.

120.Epping-Jordan JE, Compas BE, Osowiecki DM, et al. Psychological adjustment in breast cancer: Processes of emotional distress. Health Psychol 1999;18:315-26.

121.Godin G, Cote J, Naccache H, et al. Prediction of adherence to antiretroviral therapy: A one-year longitudinal study. AIDS Care 2005;17:493-504.

122.Carver CS, Lehman JM, Antoni MH. Dispositional pessimism predicts illness-related disruption of social and recreational activities among breast cancer patients. J Pers Soc Psychol 2003;84:813-21.

123.Garay-Sevilla ME, Nava LE, Malacara JM. Adherence to treatment and social support in patients with non-insulin dependent diabetes mellitus. J Diabet Complicat 1995;9:81-6.

124.Kyngas HA. Compliance of adolescents with asthma. Nurs Health Sci 1999;1:195-202. 
J 2005;46:331-40.

125.Kyngas H. Predictors of good compliance in adolescents with epilepsy. Seizure 2001;10:549-53.

126.Loffler W, Kilian R, Toumi M. Schizophrenic patients' subjective reasons for compliance and noncompliance with neuroleptic treatment. Pharmacopsychiatry 2003;36:105-12.

127.Lorenc L, Branthwaite A. Are older adults less compliant with prescribed medication than younger adults? Br J Clin Psychol 1993;32:485-92.

128. Milas NC, Nowalk MP, Akpele L. Factors associated with adherence to the dietary protein intervention in the Modification of Diet in Renal Disease Study. J Am Diet Assoc 1995;95:1295-300.

129.Seo MA, Min SK. Development of a structural model explaining medication compliance of persons with schizophrenia. Yonsei Med
130.Stanton AL. Determinants of adherence to medical regimens by hypertensive patients. J Behav Med 1987;10:377-94.

131.Stromberg A, Brostrom A, Dahlstrom U. Factors influencing patient compliance with therapeutic regimens in chronic heart failure: A critical incident technique analysis. Heart Lung 1999;28:334-41.

132.Thomas LK, Sargent RG, Michels PC. Identification of the factors associated with compliance to therapeutic diets in older adults with end stage renal disease. J Ren Nutr 2001;11:80-9.

133.Voils CI, Steffens DC, Flint EP. Social support and locus of control as predictors of adherence to antidepressant medication in an elderly population. Am J Geriatr Psychiatry 2005;13:157-65. 